Indonesian Journal of Physics and Nuclear Applications

Volume 1, Number 2, June 2016, p. 108-115

ISSN 2549-046X, C FSM UKSW Publication

\title{
Quality Management System Program of in Vitro/in Vivo Test Facilityof Boron Neutron Capture Therapy at Kartini Research Reactor
}

\author{
Widarto, Isman Mulyadi Tri Atmoko, Gede Sutresna W. \\ Reseacher of Research Centre of Science and Accellerator \\ Jl. Babarsari, PO Box 6101 ykbb, Yogyakarta 55281.
}

Received: 25 June 2015, Revised: 30 September 2016, Accepted: 10 April 2016

\begin{abstract}
Quality management system program of in Vitro / in Vivo Test Facility of Boron Neutron Capture Therapy at Kartini Research Reactor. The quality manajement system program of in vitro / in vivo test facility of Boron Neutron Capture Therapy (BNCT) methode as quality assurance requirement for utilization of radial pearcing beamport of Kartini research have been done. Identification and managementof technical specification and parameters meassurement of to the radial piercing beamport have been determined for preparing in vitro / in vivo test facility. The parameters are epithermal neutron flux is $9,8243 \mathrm{E}+05 \mathrm{n} \mathrm{cm}^{-2} \mathrm{~s}^{-1}$ and thermal neutron flux is $3,0691 \mathrm{E}+06 \mathrm{n} \mathrm{cm}{ }^{-2} \mathrm{~s}^{-1}$, radiation shielding of parafin, dimension and size of piercing radial and instrumentatin and control systemfor automatic transfer of in vitro / in vivo samplels have been documented. Management system of the documents for fullfil basic guidance to perform working job of in vitro / in vivo at the piercing radial beamport of Kartini Research Reactor in order purpose utilization of the reactor for safety worker of the radiation area, society and invironment beeing safely
\end{abstract}

Keywords : in vitro / in vivo test facility, neutron flux, radiation shielding,

\section{INTRODUCTION}

The Kartini Research Reactor is one of the TRIGA (Training Research Isotope Production by General Atomic) type nuclear reactors which still operating for $100 \mathrm{~kW}$ power level. Since operated at the first time at April 1979, the research reactor has been used for research students of Universities, many training and education on nuclear programs such as operator and supervisor TRIGA reactor and, neutron activation analysis, research and developing on utilization related with nuclear utilization. To develope the utilization, the TRIGA reactor shoul be identify around technical specification, characterization and performance since the reactor is operating in powe level weather in normal condition, trancient condition or emmergency condition.

As research reactor with low power 100 kW thermal, the Kartini Reactor has many experiment facilities for neutron activation analysis which located in Lazy Suzan (LS),
Pneumatic Transfer System, 2 radial beamports, tangential beamport, thermal column and radial piercing beamport.

In Indonesia, researchers of neutron particle has been developing to study for application cancer therapy using neutron capture therapy (NTC) by using target nuclide of boron $\left({ }^{10} \mathrm{~B}\right)$ and called Boron Neutron Capture Therapy (BNCT) methode.Such as be known that the BNCT methode many major as neutron physics with neutron source consist of nuclear reserch reactor, compact neutron generator $(\mathrm{CNG})$ and cyclorton. Preliminary developing program of the BNCT is begining to preparing test facility for in vitro / in vivo by using neutron source of radial piercing beamport of Kartini research Reactor. Known that the reactor has many neutron source facilities which can be used for neutron activation, furthermore there is one neutron activation facility which has potential for neutron activation of BNCT methode i.e the neutron source radial piercing beamport. Because the radial piercing beamport has centrifugal 
direction and pierce to biological shieding up to reactor core. By that design, the neutron flux from the reactor core will be hihgest than others. Related with potential utilization of the beamport, this facilities will be used for preparing in vitro/in vivo test facilities, it mean that many equipment and infrastructure as completion of in vitro/in vivo test facility should be caried out in once management system as working guidancepolicy of institution. Bussiness process and mecanism of management system as guidance job discription discuss about program or policy, how to carry out (performance) and supervission processing in orde has qualify product. By policy the management system should be completed document fulfil with organisation, task and responsibility, objective around many eqquipments and instruments, infrastructure, procedure, work instruction and datas notification, audio and visual. Bisides that the management system also fulfil with basic education of human resources, personal competency, on the job training skill and safety culture. Principally objective utiliztion need many objectives in purpose to fulfil radiation safety analysis for radiation worker, public and invironment.

\section{Scope}

The management system is applicable to the establishment, implementation, assessment and continual improvement for radiation facilities; activities using sources of ionizing radiation; radiation protection activities; and any other practices or circumstances in which people may be exposed to radiation from naturally occurring or artificial sources;

\section{Objective}

Management system document is to define requirements for establishing, implementing, assessing and continually improving a management system that integrates safety, health, environmental, security, quality and economic elements to ensure that safety is properly taken into account in all the activities of an organization. The main objective of the requirements for the management system is to ensure, by considering the implications of all actions not within separate management systems but with regard to safety as a whole, that safety is not compromised. Safety Requirements is applicable throughout the lifetime of facilities and for the entire duration of activities in normal, transient and emergency situations. This includes any subsequent period of institutional control that may be necessary.

\section{METHODOLOGY}

In Indonesia, preliminary study for neutron capture therapy by using BNCT method was developed by utilizing neutron source of Kartini research reactor using radial piercing beamport which has neutron flux higher than the others. with the development plan of the test facility in vitro / in vivo method of BNCT. Management process for preparing of the methodology should be put on the manuscrip as follow.

\section{Infrastrukture and Equipments.}

Indonesia has TRIGA type for low power level $100 \mathrm{~kW}$ thermal which potentialy for researh and development related with utilization of nuclear energy concerning for in vitro / in vivo test facility on field BNCT methode . Firstly research and developing preparation for in vitro / in vivo test facility using radial piercing beamport of Kartini research reaktor as neutron source facility, where the beamport has neutron flux higher than others.

As neutron source because of fission product is hapened in the reactor core than through out canal of radial pircing beamport. Nuclear reaction as fission product of neutron in reactor core could be figure out as follow. 


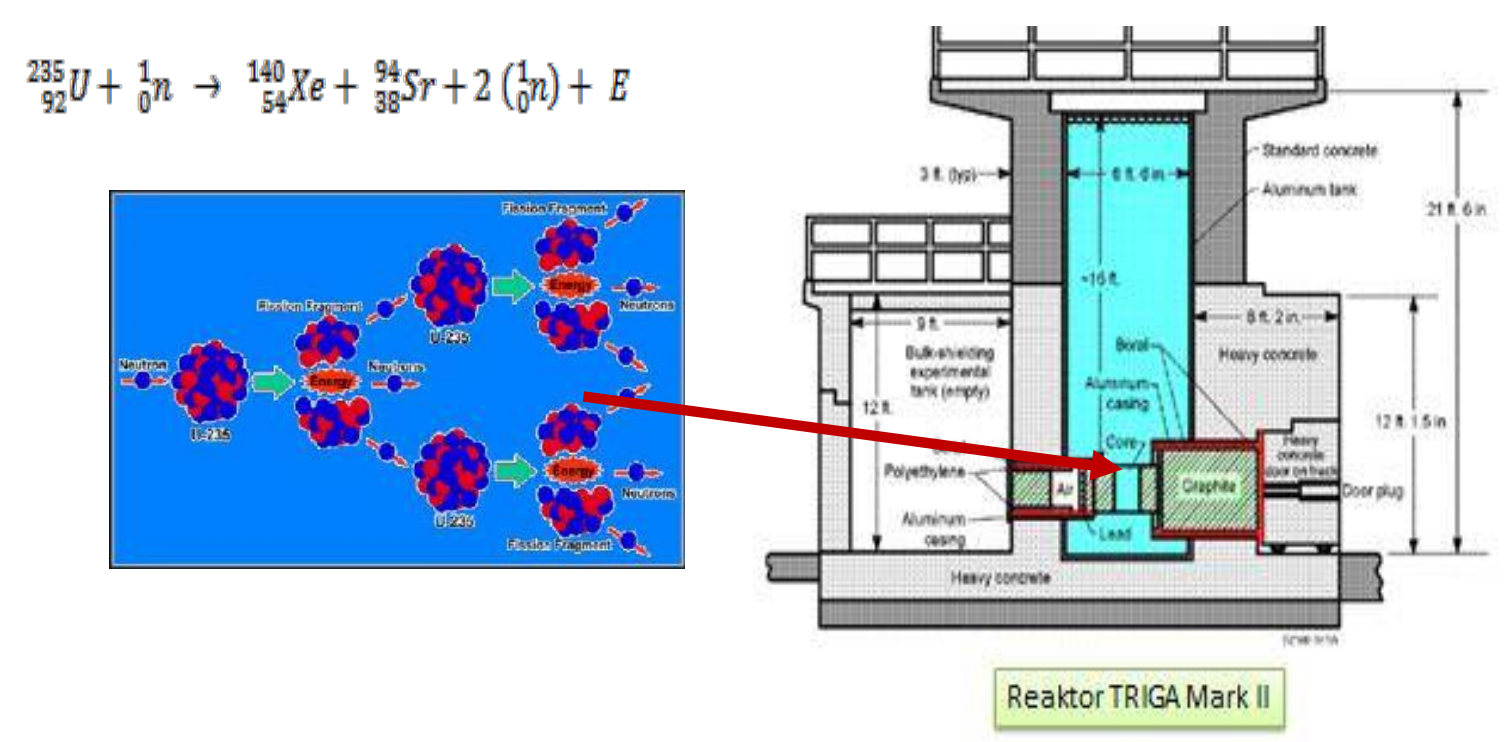

Figure 1. Vertical Cross Section of Kartini Research Reactor

Fission reaction of uranium fuel produce neutron in reactor core at Figure 1.

Neutron particle through out from the reactor core to outside of radial piercing beampor with neutron flux value is $3,0691 \mathrm{E}+06 \mathrm{n} / \mathrm{cm}^{2}$ secon for thermal neutron and $9,8243 \mathrm{E}+05 \mathrm{n} /$ $\mathrm{cm}^{2}$ secon for epithermal. Completed data of neutron flux on the long of radial piercing beamport as results by meassurement indicated at Table 1.

Table 1. Neutron fluks of radial piercing beamport of Kartini reactor.(1)

\begin{tabular}{ccc}
\hline $\begin{array}{c}\text { Distance from } \\
\text { beamport }(\mathrm{cm})\end{array}$ & \multicolumn{2}{c}{ Fluks Neutron $(\varnothing)\left(\mathrm{n} \mathrm{cm}^{-2} \mathrm{~s}^{-1}\right)$} \\
\cline { 2 - 3 }$\left(\mathrm{n} \mathrm{cm}^{-2} \mathrm{~s}^{-1}\right)$ & $\begin{array}{c}\text { Epitermal } \\
\left(\mathrm{n} \mathrm{cm}^{-2} \mathrm{~s}^{-1}\right)\end{array}$ \\
\hline 0 & $1,3264 \mathrm{E}+09$ & $1,3130 \mathrm{E}+09$ \\
25 & $4,1366 \mathrm{E}+08$ & $3,3393 \mathrm{E}+08$ \\
50 & $4,0303 \mathrm{E}+08$ & $3,9220 \mathrm{E}+08$ \\
75 & $1,0511 \mathrm{E}+08$ & $8,3272 \mathrm{E}+07$ \\
100 & $2,0128 \mathrm{E}+07$ & $1,4682 \mathrm{E}+07$ \\
120 & $8,3678 \mathrm{E}+06$ & $3,3553 \mathrm{E}+06$ \\
140 & $8,3082 \mathrm{E}+06$ & $1,5311 \mathrm{E}+06$ \\
160 & $3,0194 \mathrm{E}+06$ & $3,1597 \mathrm{E}+06$ \\
180 & $5,9255 \mathrm{E}+06$ & $4,5900 \mathrm{E}+05$ \\
200 & $5,2844 \mathrm{E}+06$ & $4,7344 \mathrm{E}+05$ \\
220 & $3,6433 \mathrm{E}+06$ & $1,2849 \mathrm{E}+06$ \\
240 & $4,4010 \mathrm{E}+06$ & $5,2958 \mathrm{E}+05$ \\
260 & $3,0691 \mathrm{E}+06$ & $9,8243 \mathrm{E}+05$ \\
\hline
\end{tabular}

Related with safety requirements aspect of radiation protection considering with utilization for in vitro / in vivo test facility, in front of the hole radial piercing beamport should be covered with shieding material made of parafin block, such as indicated at Figure 2

Transfer system for sample of in vitro / in vivo target from the irradiation facility i.e. radial piercing beamport terminated outside far away around 3 meter, to fulfil safety requirements aspect of state regulatory.

Basic design of equipment for transfer system of sample in vitro / in vivo test facility also should be fulfil safety requirement aspect of radiation protection (Figure 4). So that terminal of sample should be far away from the target, and for the terminal put on 3 meter out side of radial piercing beamport as irradiation facility (FI) .

\section{Management System Of Radiation Source In Vitro / In Vivo Test Facility.}

The main purpose uttilization nuclear technology is safety requirements for radiation worker, public domain and invironment. Safety requirements document defines the requirements for establishing, implementing, assessing and continually improving a management 
Widarto, Isman Mulyadi Tri Atmoko, Gede Sutresna W., Quality Management System Program of in Vitro/in Vivo Test Facilityof Boron Neutron Capture Therapy at Kartini Research Reactor

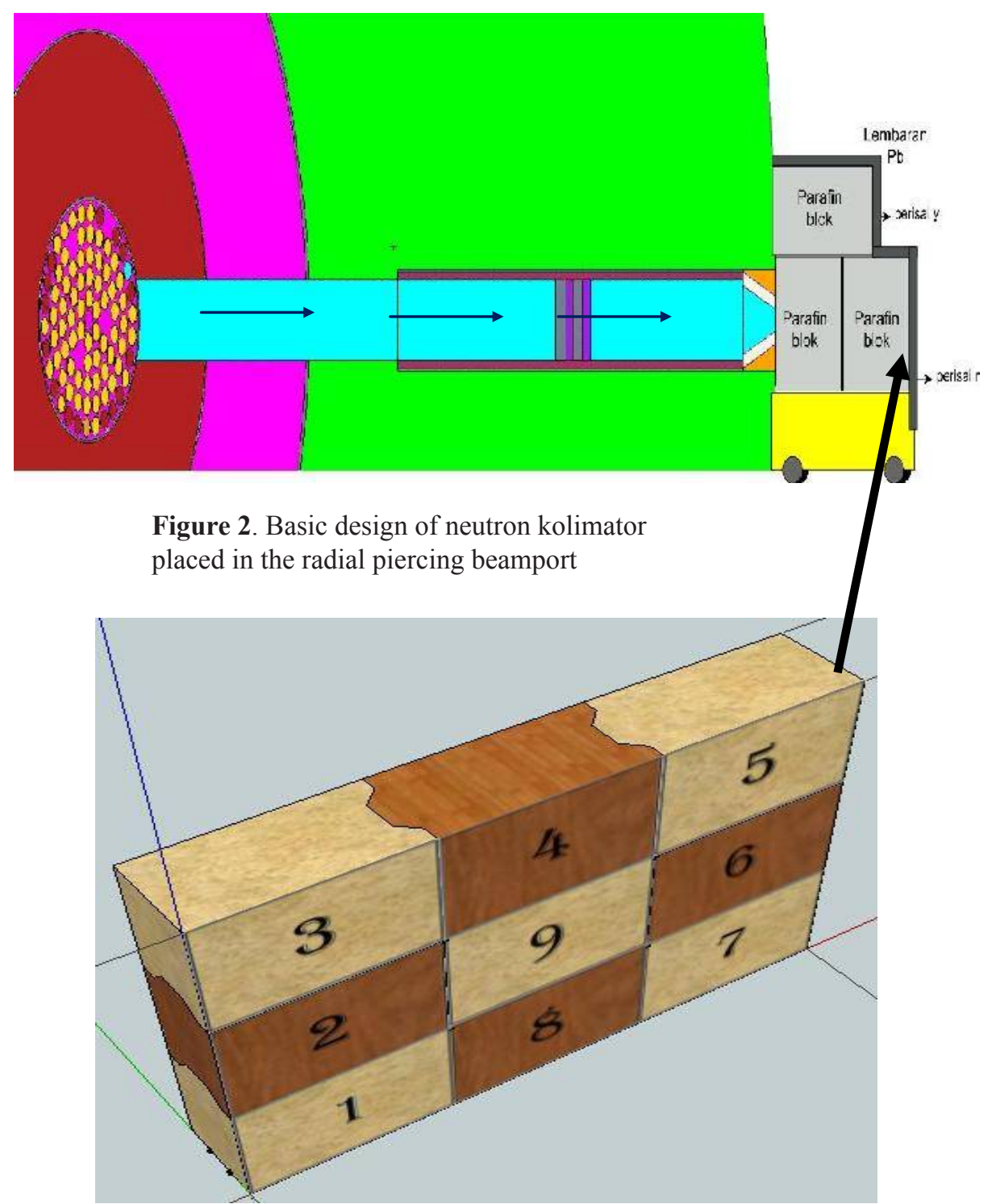

Figure 3. Radiation shielding of parafin block for protection radiation.

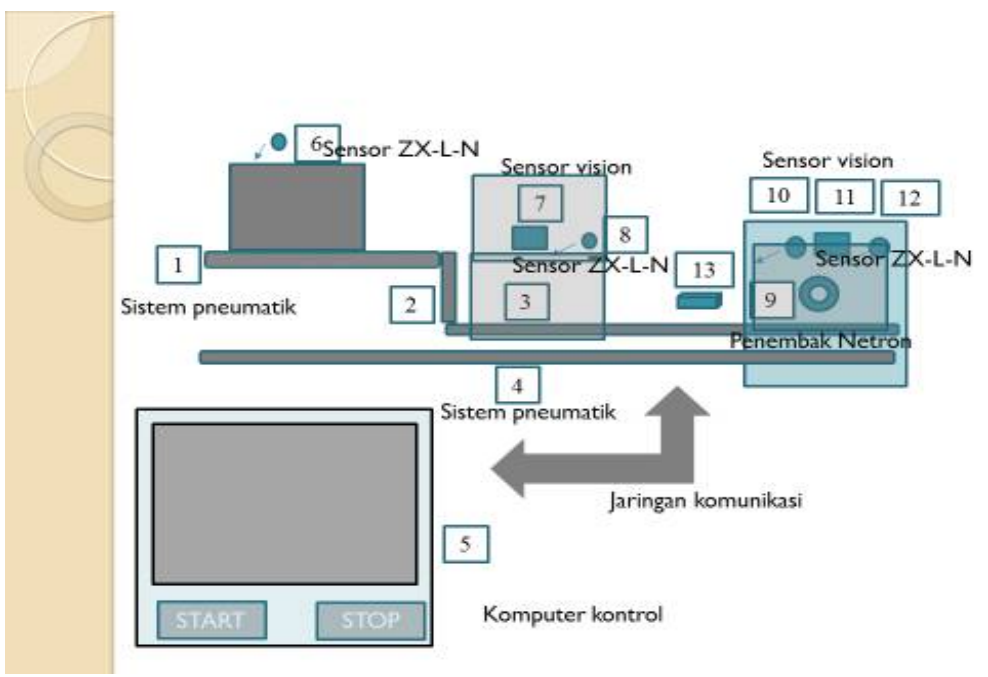

Figure 4 a. Instrumentation and Control System 


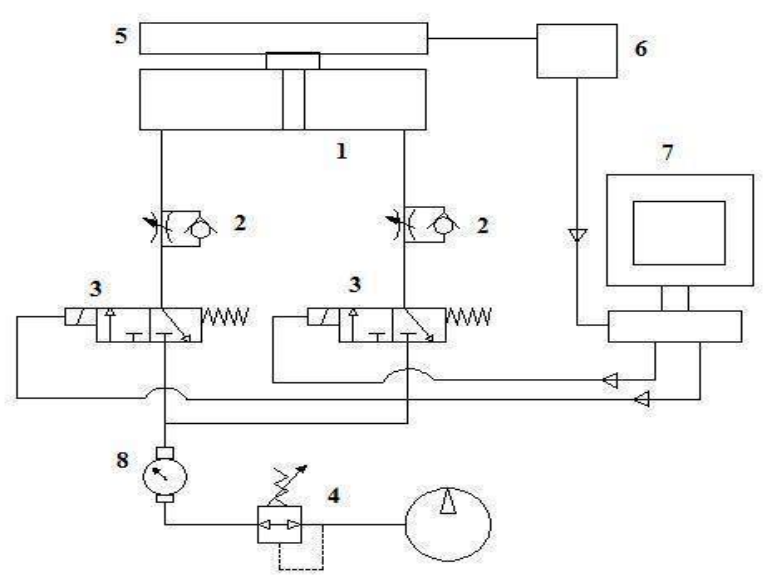

Figure 4b. Pneumatic transfer system

1. Silindrical pneumatik double action rodless

2. one direction control system

3. Control on/off solenoid

4. Source and control pressurized air.

5. Linear Potensiometer

6. Sensor Unit

7. Amplifier ang control unit.

8. Pressure meter.

system. A management system designed to fulfil these requirements integrates safety, health, environmental, security ${ }^{1}$, quality ${ }^{2}$ and economic $^{3}$ elements. Safety is the fundamental principle upon which the management system is based. These requirements must be met to ensure the protection of people and the environment and they are governed by the objectives, concepts and principles of regulatory safety standardfundamentals documents [1].

Content of thedocument supports the achievement of the two general aims of the management system, that are :

- To improve the safety performance of the organization through the planning, control and supervision of safety related activities in normal, transient and emergency situations; and

- To foster and support a strong safety culture through the development and reinforcement of good safety attitudes and behaviour in individuals and teams so as to allow them to carry out their tasks safely.
Safety requirements document should bee covers the security of facilities, nuclear material and sources of radiation only to the extent that security measures for physical protection are essential to safety and the failure of such measures has consequences for safety.

Content of the document management system is based on two key concepts:

- that work may be structured and interpreted as a set of interacting processes; and

- that all individuals involved contribute to achieving safety and quality objectives.

The requirements established in the document may be used by organizations in the following ways:

- As the basis for the management systems of organizations directly responsible for operating facilities and activities and providing services.

- As the basis for the regulation of these facilities and activities by the regulatory body;

- As the basis for the management systems of the relevant regulatory bodies [6];

- By the operator, to specify to a supplier, via contractual documentation, any specific requirements of the safety requirements document that must be included in the supplier's management system for the supply and delivery of products ${ }^{1}$.

Management system should be completed with organization to support achievement of the job discription in the in vitro/in vivo test facility which has been fulfil in the document, such as Figure 6. follow.

\section{Task and Responsibility}

Each task in the field of cooperative organizations are : 


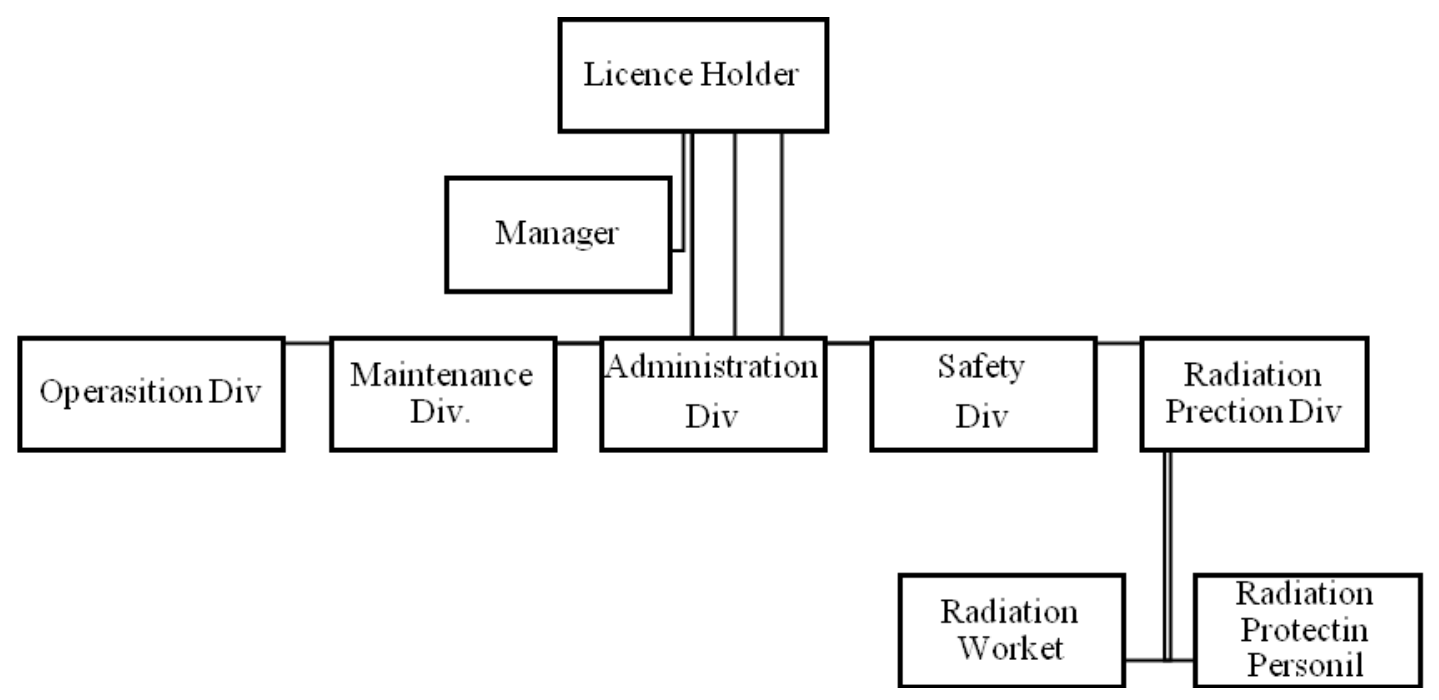

Figure 6. Organization of in vitro in vivo test facility.

\section{License Holder}

Licence holder has task for establishing, implementing, assessing and continually improve the management system in accordance the organization purpose contribute to the achievement goals organization.

\section{Manager}

Senior management called manager means the person (or group of people) whowhich directs, controls and assesses an organization at the highest level.

Manager responsible and authorized to coordinate the development and implementation of management systems, as well as the assessment and continuous improvement, resolve any conflicts that may occur between the management requirements of the implementation of the management system; and report to the license holder's performance management system, including the effects on safety and safety culture, and any need for improving the product.

\section{Operation Division}

Task and responsibiliti ot the Operation Division are :
- To coordinate operation of system, structure and componen of in vitro / in vivo test facilities,

- Shift sceduling to operate the system, structure and componen of in vitro / in vivo test facilities

\section{Maintenance Division}

Task and responsibility of the Manintenace

Division are :

- Planning, coordinating and implementing of mechanical treatment.

- mechanical treatment facilities.

- treatment of civil facilities and structures

\section{Radiation Protection Divission.}

Task and responsibility of the Radiation Protection Division are :

- Supervice to safety aspec of nuclear safety

- Supervise the implementation of protection and safety program

- Reviewing the effectiveness of the protection program and

- Protection and Radiation Safety program 


\section{Safety Division.}

Task and responsibility of the Safety Division are :

- evaluation and promotion of nuclear safety

- coordinating safety engineering

- safety management committee

- safeguards

\section{Services danAdministrasi}

Task and responsibility of the Services danAdministrasi Division are :

- environment, administration, relations with the public

- computerized management system improvement

- documentation system

- personnel problems and employee

- financial and salaries

- distribution and supply inventory

\section{RESULT \& DISCUSSION}

The Kartini reseach reactor is designed for low power and operated for $100 \mathrm{~kW}$ thermal aimed for education and training operator / supervisor of TRIGA reactor, Neutron Activation Analysis (NAA), laboratorium work, innovation research and experimentation final project for students of Univesities in nuclear technology utilization and developmrnt. The reactor TRIGA type has advantages in terms of: simple, safe, and easy in maintenance, and flexible for inovation research purposes. Related with this discussion for inovation research, the Kartini reactor will be used for developing utilization preparing in vitro/in vivo test facility using radial piercing beamport. In orde fulfil safety requirements and suitable with regulation the program should be covered with management system as guidence for quality of product. Main policy the utilization for research inovation such as preparing for in vitro / in vivo test facility at the radial piercing beamport of Kartini research reactor is safety requiremen of radiation protection aspect which covered in the quality manajement system. So that management system contain the program for quality of product refers to the degree to which a product, process or service satisfies specified requirements and supervising. The term of management system reflects and includes the initial concept of 'quality control' (controlling the quality of products) and its evolution through quality assurance (the system to ensure the quality of products) and 'quality management' (the system to manage quality). The management system is a set of interrelated or interacting elements that establishes policies and objectives and which enables those objectives to be achieved in a safe, efficient and effective manner. Economic objectives should be included in the list of elements that have to be integrated, as it is recognized that economic decisions and actions may introduce or may mitigate potential risks.

Integrated management system requirements defined in this disscussion cover topics that either relate directly to safety or are part of the managerial framework without which safety cannot be ensured and maintained. Thus topics such as management commitment, communications and other aspects are included from the perspective of seeking to enhance safety aspect as well as performance.

A graded approach based on the relative importance to nuclear safety aspect of each item, i.e realistic pranning, service or process, supervising and assessing shall be implemented. The graded approach shall reflect a planned and recognized difference in the applications of specific quality management system requirements.

In general, the highest grade should require the most stringent application of the quality management system requirements. 
The following are examples of topic areas where grading should be applied:

- Type and content of training

- Amount of detail and degree of review and approval of instructions

- Need for and detail of inspection plans,

- Degree of in-process reviews and controls,

- Requirements for material traceability

- Type of assessment,

- Records to be generated and retained.

\section{CONCLUSION}

Nuclear safety requirement aspect shall be the fundamental consideration in the identification of the items, fulfil with realistic planning, services and processes, supervising and assessing to which the quality management system programme applies to the Kartini research reactor for inovation of reseach and development of utilization in vitro / in vivo test faciliti of BNCT methode.

Basically the Kartini reseach reactor can be utilized for researh inovation and developing for preparing in vitro / in vivo test facility of BNCT methode using radial piercing beamport, however should be covered with safety requirement management system and must be implemented consistenly.

\section{ACKNOWLEDGMENT}

This paper with the topic " Quality Managemen Systemof In Vitro In Vivo Test Facility Of Boron Neutron Capture Therapy (BNCT) Using The Kartini Research Reactor was supported by Center for Accelerator Science and Technology (PSTA) BATAN Yogyakarta. For this matter state thank very much to Prof. Yohannes Sardjono as a chairman of the consortium of BNCT, Buyung Edi Prabowo, S.Si as yunior researcher, and many others yunior researcher which have join to BNCT Consortium such as Ilma,S.T, Bambang, S.T and Dwi, M.Si and Anggra, M.Si, for assistance with particular technique and methodology, and many others person which I can't mention each other. I'am thank you very much, hopfully we will be lucky in the next days.

\section{REFERENCE}

1. Analisis Pengembangan Fasilitas Uji In Vitro/In Vivo Metode Boron Neutron Capture Cancer Therapy Dengan Memanfaatkan Potensi Neutron Beamport Untuk Pendayagunaan Reaktor Triga Kartini, Widarto*, Isman Mulyadi $\mathrm{T}^{*}$, Puradwi IW*, Tri Nugroho HS*

2. Management System for Facilities and Activities, GS-R-3, IAEA, 2006

3. Application of The Management System for Facilities and Activities, IAEA Safety Standart Series, GS-G-3-1, IAEA, 2006

4. Quality Assurance Standards: Comparison Between IAEA 50-C/SG-Q AND ISO 9001:1994, IAEA-TECDOC-1182 ISSN 1011-4289, VIENNA, 2000,

5. Program Jaminan Mutu Operasi dan Perawatan Reaktor Kartini, Dok. No. PJM OPRK/APB-04, 2012.

6. Peraturan Kepala BAPETEN No.4 Tahun 2013 Tentang Proteksi Radiasi dan Keselamatan Radiasi Dalam Pemnafaatan Tenaga Nuklir.

7. Perka Kepala BAPETEN No. 4 Tahun 2010 Tentang Sistem Manajemen Fasilias dan Aktivitas. 